\title{
Experimental evidence that adult UV/yellow colouration functions as a signal in blue tit families — but only for parents
}

\author{
Jorge García-Campa ${ }^{1}$ (D) $\cdot$ Wendt Müller ${ }^{2}$ Judith Morales ${ }^{1}$
}

Received: 25 December 2021 / Revised: 27 January 2022 / Accepted: 31 January 2022 / Published online: 10 February 2022

(c) The Author(s) 2022

\begin{abstract}
In bi-parental species, reproduction is not only a crucial life-history stage where individuals must take fitness-related decisions, but these decisions also need to be adjusted to the behavioural strategies of other individuals. Hence, communication is required, which could be facilitated by informative signals. Yet, these signalling traits might have (co-)evolved in multiple contexts, as various family members usually meet and interact during reproduction. In this study, we experimentally explored for the first time whether a colourful plumage trait in adults acts as a signal that regulates multiple intra-family interactions in a bird species, the blue tit (Cyanistes caeruleus). We expected that an experimental reduction of adults' UV/yellow reflectance (i.e. a reduction of apparent individual quality) should affect the behavioural strategies of all family members. We found evidence for this at least in adults, since the partners of UV-blocked individuals (either males or females) increased their parental investment - perhaps to compensate for the apparent lower condition of their mates. As the UV-blocked adult did not change its provisioning behaviour, the partner presumably responded to the manipulated signal and not to a behavioural change. However, the offspring did not co-adjust their begging intensity to the experimental treatment. It is thus possible that they responded to overall parental care rather than the signal. These results suggest that UV/yellow colouration of adult blue tits may act as quality signal revealing the rearing capacity to mates.
\end{abstract}

\section{Significance statement}

How parents respond to signals of genetic or phenotypic quality of their mates has received significant attention. However, previous studies have primarily focused on the receiver's response and have not always controlled for the signaller's behaviour and its investment in reproduction. Our results provide the first experimental evidence that ultraviolet (UV)/yellow colouration acts as a signal of parental quality in the blue tit. Parents responded by increasing their effort when paired with UV-blocked (low-quality) mates, while controlling for the mate's behaviour. We argue that the reduced expression of the signal triggered a compensatory response in the mate. Interestingly, both males and females responded similarly to changes in mate's UV/yellow reflectance, suggesting similar rules over investment in response to this trait. However, nestlings, a potential (and often neglected) set of observers of parental signals, did not change their behaviour when raised by an UVblocked (= low-quality) parent.

Keywords Communication $\cdot$ Signals $\cdot$ Parental care $\cdot$ Differential allocation $\cdot$ Compensation $\cdot$ Ultraviolet colouration

Communicated by S. Pruett-Jones

Jorge García-Campa

jgarciacampa@gmail.com

1 Department of Evolutionary Ecology, National Museum of Natural Sciences - Spanish National Research Council (CSIC), c/ José Gutiérrez Abascal 2, 28006 Madrid, Spain

2 Department of Biology, Behavioural Ecology and Ecophysiology Group, University of Antwerp, Universiteitsplein 1, 2610 Antwerp, Wilrijk, Belgium

\section{Introduction}

Communication is a co-evolutionary process that involves the transfer of information from a sender to a receiver (Bradbury and Vehrencamp 2011). This process is subject to selection, where both senders and receivers try to optimize their fitness as a result of their interaction (Zahavi 1981). Communication usually involves conspicuous traits (i.e. colourations or vocalizations) that can be costly to produce and maintain (Zahavi 1975; Hamilton and Zuk 
1982). Therefore, these traits typically reflect health or condition (Folstad and Karter 1992) and may thus function as signals of quality. Individuals respond to these signalling traits to modulate fitness-related decisions like where to live, what to eat, and whom to interact with (Danchin et al. 2004).

One important time point where fitness-related decisions require communication is during reproduction, when, at least in bi-parental species, individuals must (co-)adjust their behaviour, such as the amount of parental care they are going to provide (Iserbyt et al. 2019). Because parental investment in current reproduction comes at a cost to parents in terms of reduced survival and future reproduction (Stearns 1992), each parent would benefit from shifting a greater share of parental investment to their mate (Trivers 1972). Furthermore, to enhance reproductive success, caregivers should adjust their level of investment according to the quality of the current reproductive event, which depends on (i) environmental conditions like habitat quality (CapillaLasheras et al. 2017) or resource availability (Hakkarainen et al. 1997), (ii) their own condition and hence their rearing capacity (Ots and Hõrak 1998), and (iii) the condition of their mate, which can be derived from signals of quality (Velando et al. 2006).

How individuals respond to signals of genetic or phenotypic quality has received significant attention (Sheldon 2000; Harris and Uller 2009; Ratikainen and Kokko 2010). On the one hand, individuals are expected to increase their effort when paired with highly ornamented mates either because the offspring will inherit the mate's high quality conveyed by ornamentation (i.e. the classical scenario of positive differential allocation; Burley 1986, 1988), or because highly ornamented mates seek more extra-pair copulations and thus neglect their parental effort (Kokko 1998; Ratikainen and Kokko 2010). On the other hand, individuals could also increase their investment when paired with poorly ornamented mates (or in general poor quality mates) in order to improve on an unfortunate situation (reproductive compensation; Gowaty et al. 2007; Gowaty 2008). Reproductive compensation might be more advantageous if the reduction of the mate's ornamentation occurs unexpectedly after fertilization, when the offspring genetic quality is not at stake (Morales et al. 2012), or at late stages of offspring development, when most of the strenuous parental effort has already been performed and the extra-investment could be of short duration (Savage and Hinde 2019). The optimal parental care strategy might thus be context-dependent, and it may also be highly dependent on the behaviour of the signaller (Ratikainen and Kokko 2010). However, previous studies have primarily focused on the receiver's response and have not always controlled for the signallers' behaviour and its investment in reproduction (but see, for example, Sanz 2001; Soler et al. 2008; Doutrelant et al. 2008).
Additionally, studies have generally focused on a single set of receivers, for example, the focus has been on the response to signals expressed by mates, but not on offspring responses to parental signals. However, family members (mates and offspring) usually coincide in time and space, and the information conveyed by signallers can be used by multiple family members simultaneously. Hence, the family is a social environment in which signals can function in multiple contexts (Morales and Velando 2013). To take an example, the size of the red-dot on the bill of the yellow-legged gull, Larus michaellis, affects a mate's parental investment (Morales et al. 2009) and at the same time, it induces chick begging (Velando et al. 2013). Similarly, in the burying beetle, Nicrophorus vespilloides, chemical profiles not only play a role in mate-mate recognition (Steiger et al. 2008) but also trigger larvae begging (Smiseth et al. 2010). However, despite the large number of studies about the role of adult signals on parental decisions, very few have assessed their potential concomitant effects on offspring.

Here, we tested the hypothesis that an adult structural trait (i.e. ultraviolet (UV) yellow breast plumage colouration) functions as a signalling trait that affects the mate's parental effort as well as the offspring's begging behaviour. To test this, we experimentally blocked the UV reflectance of yellow breast feathers in the blue tit (Cyanistes caeruleus), a socially monogamous passerine with bi-parental care. In this species, the adults exhibit yellow breast feathers, a carotenoid-based trait (Jacot and Kempenaers 2007), which also reflects light in the UV region of the reflectance spectra, due to the reflective properties of the feathers' keratin structure (Shawkey and Hill 2005). It is well known that the carotenoid-based component of the yellow breast colouration signals different aspects of individual quality (e.g. Senar et al. 2002; Hidalgo-Garcia 2006; Doutrelant et al. 2008, 2012; Ferns and Hinsley 2008; del Cerro et al. 2010; García-Navas et al. 2012; Midamegbe et al. 2013; Ferrer et al. 2015; in the great tit Parus major, see also Senar and Quesada 2006; Pagani-Núñez and Senar, 2014). However, the current study focuses on the role of UV reflectance of yellow breast feathers, which has as yet rarely been studied, given the evidence for UV-based structural colouration as a signal of individual quality in parents, as shown for a variety of feather traits in adult blue tits (blue crown feathers: Szigeti et al. 2007; Henderson et al. 2013; Midamegbe et al. 2013; white cheek: Badás et al. 2018; see also Doutrelant et al. 2020 for a review). In adults, UV reflectance of yellow breast feathers is higher in non-parasitized birds (Janas et al. 2018). In blue tit juveniles, this trait signals individual condition (Morales and Velando 2018). Additionally, as UV reflectance is more easily perceived by birds inside a cavity than visible carotenoid-based reflectance (Hunt et al. 2003; Avilés et al. 2006; Wiebe and Slagsvold 2009; Wẹgrzyn et al. 2011), we expect UV to be more likely to mediate 
parent-offspring interactions than carotenoid-based yellow colouration (see also Tanner and Richner 2008; Morales and Velando 2018, for parental favouritism towards UV-reflecting nestlings).

At the end of the nestling period, we reduced the UV/ yellow reflectance in one of the parents in each experimental nest to simulate the signal expression of a low quality individual. We predicted that a parent would increase its effort when mated with a UV-blocked individual, in order to compensate for an unexpected short-term reduced condition and thus low rearing capacity of their mate. We expected that UV-blocked individuals themselves would not change their own parental effort, given that their inherent quality was not changed but only their external appearance (i.e. signal expression). Offspring should perceive UV-blocked parents as poor-quality caregivers, and thus redirect their begging behaviour towards the other parent. Preferring high-quality caregivers based on signalling traits may allow nestlings to maximize their reward (Velando et al. 2005, 2013). Finally, we may hypothesize that nestlings raised in UV-blocked nests should gain more body mass and survive better than those in control nests due to an overall increased parental investment.

\section{Material and methods}

\section{Ethics statement}

The experiment involved manipulation of the UV reflectance of individuals. This manipulation lasted less than $5 \mathrm{~min}$ and did not involve blood sampling. Plumage colour manipulation had no apparent negative effects on health or survival (e.g. Delhey et al. 2006, using a similar manipulation in blue tit adults). Video-recording inside the nest appeared to have no effect on the behaviour or reproductive performance of wild birds, since parents resume offspring feeding normally in less than $10 \mathrm{~min}$ and sometimes even in the presence of researchers. In our previous experiments in the study area, none of the experimental blue-tit nests was deserted during or after video-recording (Morales and Velando 2018).

\section{Study area and study species}

The study was carried out in Miraflores de la Sierra, Madrid, central Spain $\left(40^{\circ} 48^{\prime} \mathrm{N}, 03^{\circ} 47^{\prime} \mathrm{W}\right)$ during the breeding season of 2018. We studied a wild population of blue tits breeding in nest-boxes located in a deciduous forest, mainly dominated by Pyrenean oak (Quercus pyrenaica). In this bird species, nest construction and incubation is carried out by females, but both adults contribute to offspring provisioning, which is crucial for offspring growth and survival (Schwagmeyer and Mock 2008).
In the study area, blue tits raise one clutch per season and may raise up to 15 nestlings (average brood size in the study population: $9.6 \pm 1.8 \mathrm{SD} ; n=464$; range $4-15$ ). Therefore, a blue tit family constitutes a complex social network, which connects a considerable number of family members that meet for a short period of time and that interact to adjust their decisions over parental care.

\section{General methods and experimental manipulation of UV/yellow reflectance}

At the beginning of the breeding season, nest boxes were visited every 3 days to register laying date, and every 2 days for the onset of female incubation and hatching date (= day $0)$. Two days before the expected hatching date, all clutches were reciprocally cross-fostered between two nests as part of another experiment. All clutches exchanged were similar in clutch size and laying date ( \pm 2 eggs and days respectively).

In the second week of the nestling period, we captured adults with nest-box traps. The first adult captured in each nest (hereafter, the treated individual) was randomly assigned to either an experimental UV-blocked group, in which we reduced the UV/yellow reflectance of breast feathers, or to a control group ( $n=31$ UV-blocked nests and 29 control nests). UV-blocked nests and control nests did not differ in hatching date $\left(1=1\right.$ st April: $n_{\text {Control }}=29$; mean $\pm S E=53.69 \pm 1.03$; and $n$ UV-blocked $=31 ;$ mean $\pm S E=$ $\left.54.71 \pm 0.99 ; F_{1,58}=0.51 ; p=0.48\right)$. We applied the UVblocked treatment to 15 males and 16 females from different nests by using a yellow marker on breast feathers (Edding 4500, code 005; see Morales and Velando 2018, for this study population; see also Galván et al. 2008, in great tits). As a result, UV-blocked adults had lower UV reflectance after manipulation than prior to manipulation (see Fig. 1). Although colour manipulation likely results in an artificial phenotype that is not identical to natural colouration, the spectra of UV-blocked individuals were apparently within the natural range of observed variation (see Fig. S1). The adult that was captured first was marked on the back feathers with a white permanent marker (Edding 751, code 049) in order to distinguish parents during video recording. At control nests, we applied the same yellow marker to the first adult captured but only on the inner tail feathers, not on breast feathers ( $n=12$ males and 17 females from different nests; hereafter control-treated individuals). This was done in order to block UV reflectance of a similar-sized region as in the experimental group to control for the possibility that the marker has non-desirable side-effects. The controltreated adult was also marked with white on the back. In all UV-blocked and control nests, the second adult captured did not receive any colour manipulation.

The original colour of yellow breast feathers was measured using a portable spectrophotometer (JAZZ, Ocean 
Fig. 1 Average reflectance spectra from the breast feathers of 7 blue tit adults ( 3 males and 4 females) before and after UV colour manipulation (continuous line and dashed lined, respectively)

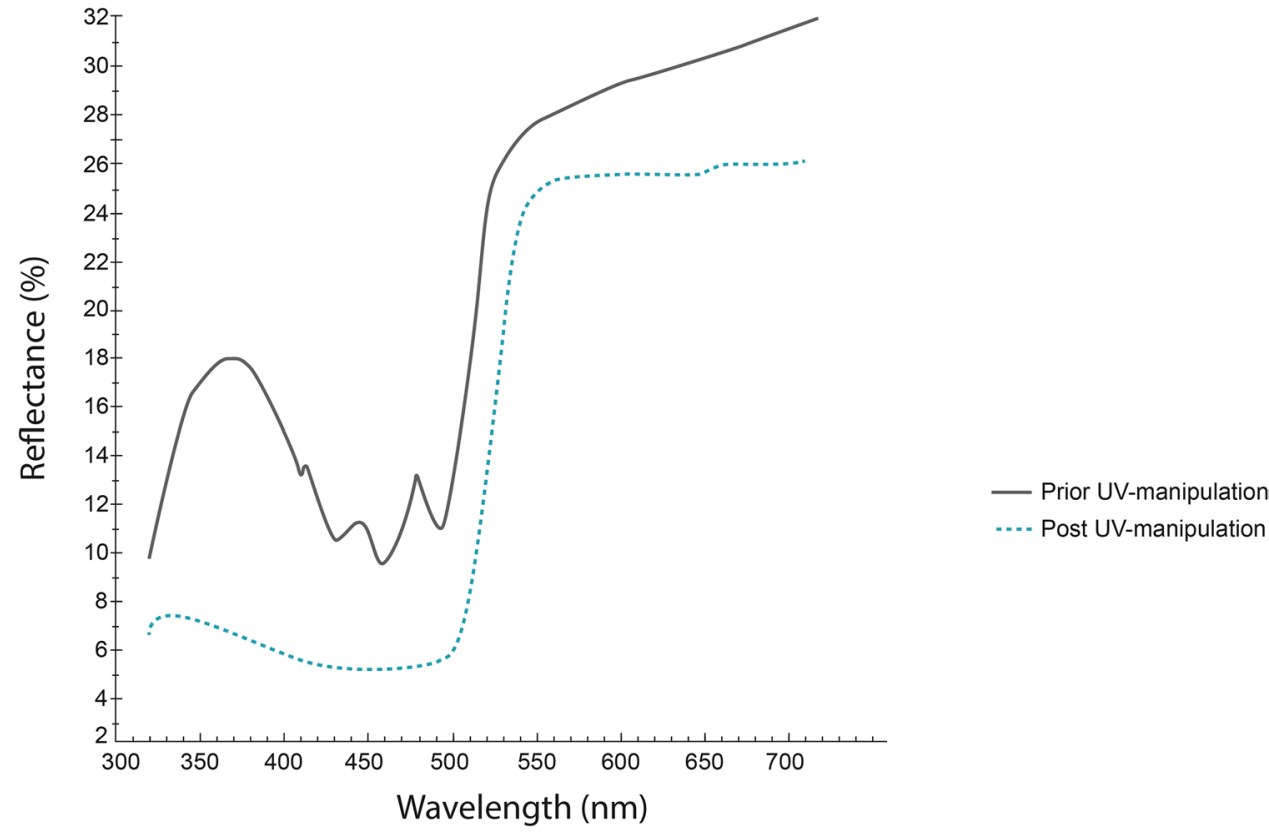

Optics), and UV chroma was calculated as reflectance in the UV range divided by total reflectance in the avian visual range $\left(R_{300-400} / R_{300-700}\right.$; following Johnsen et al. 2003, $2005)$. Prior to treatment, UV-blocked and control-treated individuals did not differ in UV/yellow chroma $\left(F_{1,54}=\right.$ $0.373 ; P=0.54)$.

We captured adults until 1 day before the video recording, so that the manipulation could be perceived by all family members at least during 1 day (average number of days elapsed between plumage manipulation and video recording: $3.51 \pm 0.71$ SD days; range $1-4$ days; $n=56$ ). We did not recapture individuals, but similar experimental studies using UV blockers (applied on crown feathers) have found that treatment lasted at least 5 days (Korsten et al. 2007; Vedder et al. 2008). Thus, it is very likely that the treatment in the current study lasted at least until the recording day for all nests. On day 12 after hatching, all nestlings were ringed, weighed, and individually marked on the head or wings with the same white marker used for adults. We also collected 3-5 breast feathers per nestling for molecular sexing (see Supplementary material). On day 13 , we video-recorded all nests to register the behaviour of all family members during the feeding bouts. Finally, all nests were visited after day 20 to establish the number of nestlings that fledged at the nests (i.e. fledging success).

\section{Video recordings and behavioural analyses}

On day 12 , the original nest-box was substituted by a recording nest-box with a camera decoy so that the blue tit pair could become familiar with the set-up before recording. The recording nest-box consisted of a similar-sized nest-box that had a ceiling opening with a black plastic cover where we placed the camera. There is some individual variation in the sensitivity to any kind of changes at the next box. However, the proportion of individuals not showing up during the video recordings is not greater than for any other method, and this methodology has successfully been applied previously (e.g. Morales and Velando 2018). On day 13, we recorded during $1.5 \mathrm{~h}$ the behaviour of all family members during parental provisioning by placing a night-vision video camera on the recording nest box (DX, 8 LED and $180^{\circ}$ vision, China) at an approximate distance of $10 \mathrm{~cm}$ from the nest. In total, we obtained the feeding behaviour for all nests except four ( 3 UV-blocked nests and 1 control nest). Filming took place between 0800 and $1300 \mathrm{~h}$ in all cases except in one nest that was recorded during the afternoon due to intense rain in the morning. Thus, all videos were recorded under favourable weather conditions. However, we excluded 14 nests in which we did not detect one of the adults during the whole video observation (the first adult captured did not appear in 3 nests and the second adult captured did not do so in 11, i.e. 5 UV-blocked nests and 9 control nests). Thus, we ensured that all behavioural observations corresponded to nests with bi-parental care. Nonetheless, including monoparental nests led to similar results (see Tables S5, S6, S7, and S8). The final sample size for statistical analysis was thus 42 nests (23 UV-blocked nests and 19 control nests). We were unable to differentiate the adults in two videos belonging to one nest because the white marks on the back could not be distinguised, although they were clearly two different individuals, so for these two videos, we could not analyse feeding variables for each parent separately, but we did include them in the models of total feeding rates. In one 
nest, both adults fed during the video recording but only one fed during the scoring time. Thus, this nest was included in the analyses. However, results remain qualitatively similar if this nest is excluded (see Tables S5, S6, S7, and S8).

We recorded each nest during $1.5 \mathrm{~h}$ and quantified behaviour for $30 \mathrm{~min}$ per nest. The first $30 \mathrm{~min}$ were excluded to avoid possible disturbance due to the researcher's presence after leaving the camera on the nest, and the subsequent 30 min were analysed. Feeding rates registered during 30 min are highly correlated with those registered during $1 \mathrm{~h}$ (Pearson's $r=0.84, P<0.001, N=45$, data from Morales and Velando 2018), and hence provide a reliable estimate of the rate of parental provisioning for twice as long. Video recordings were performed between 8:00 and 13:00, except 1 video that was recorded between 19:00 and 21:00, due to rainfall during the morning. To minimize observer bias, blinded methods were used when all behavioural data were recorded.

For each feeding event, we registered (i) whether the adult was marked or not, (ii) the size of the prey it provided, and (iii) nestling begging intensity. Prey size was rated on a 3-point scale: $1=$ small (equal or shorter than the adult beak), 2 = medium (larger than the beak but smaller than the adult's head), and $3=$ large (bigger than the adult's head) (see Morales and Velando 2018). To establish begging intensity, we rated it on a 5-point scale for each individual nestling, following Kölliker et al. (1998): $0=$ calm, $1=$ weak gaping, $2=$ gaping and neck stretched, $3=$ gaping, neck stretched, and standing, and $4=$ gaping, neck stretched, standing, and wing flapping. All these variables were registered by an observer who was unaware of treatment. Once all behavioural variables were registered, the feeding rates per nest and average prey size was obtained for both parents together (i.e. allowing to identify changes in overall levels of parental care) and for each parent separately (i.e. allowing to study individual responses). For each individual nestling, we calculated the average begging intensity shown during all the feeding events for both parents together and separately.

\section{Statistical analyses}

For all parental behavioural variables, we ran three different models: (i) total number of feeding bouts and average prey size for both parents, to check whether care levels of both parents combined were affected by treatment, (ii) number of feeding bouts and prey size of the treated individual in each nest (either UV-blocked or control-treated), and (iii) number of feeding bouts and prey size of their partner, in order to facilitate interpretation. Feeding bouts and prey size were explored with linear models. In these models, we included nest treatment (UV-blocked or control), the sex of the treated adult, brood size at day 13 , and days elapsed from treatment to video recording (hereafter, days after treatment) as predictor variables. Since treatment effects may differ between the sexes, we included the interaction between treatment and sex of the treated adult in all the models. In the models exploring the behaviour of each parent separately, we additionally included the corresponding behaviour (feeding bouts or prey size) of the mate as predictor variable.

Nestling begging intensity was the average of the scores registered during the whole observation period and followed a normal distribution. We thus explored the effect of treatment with a mixed model that included nest ID as a random factor. In this model, we included treatment, sex of the treated adult, the interaction between treatment and sex of the treated adult, and sex of the focal nestling, brood size, and days after treatment. In the model of begging intensity directed to the treated parent (either UV-blocked or control-treated), we controlled for the average begging intensity directed to the mate, and vice versa. Similarly, nestling body mass followed a normal distribution and was analysed using a mixed model with nest ID as a random factor. In this model, we included treatment, sex of treated adult, nestling sex, brood size, days after treatment, and the interaction between treatment and sex of treated adult. In all mixed models, degrees of freedom were obtained using the Satterthwaite approximation. Fledging success (i.e. number of offspring that fledged) was analysed using a generalized linear model with Poisson distribution and data were not over-dispersed so we did not have to control for it. In this model, we included treatment, sex of treated adult, brood size, days after treatment, and the interaction between treatment and sex of treated adult as covariates.

We used SAS 9.4 (SAS Inst., Cary, NC, USA) for all statistical analyses. When non-significant $(\alpha=0.05)$, the interaction between treatment and sex of the treated parent was removed. Normality, independence and homoscedasticity were explored by analysing model residuals, and all tests were conducted by using type III sums of squares.

\section{Results}

\section{Feeding bouts and prey size}

Treatment significantly affected the total number of feeding bouts performed (Table 1); UV-blocked nests received overall more feeding bouts than control nests $(P=0.033$; mean \pm SE: $19.48 \pm 1.66$, and $15.63 \pm 1.43$, respectively). When analysing the behaviour of each parent separately, treatment did not affect the number of feeding bouts of treated parents, either UV-blocked or control-treated (Table 1; Fig. 2). Also, in accordance with our prediction, there was a significant effect of treatment on the feeding behaviour of the partner; partners of UV-blocked individuals provided more feeding bouts than partners of control-treated individuals (Table 1; 
Table 1 General lineal models (LMs) showing the effects of treatment on the number of feeding bouts performed by both parents and by each parent separately (i.e. the treated adult and the partner). Treated refers to UV-blocked individuals in UV-blocked nests and control-treated ones in control nests. The interaction between treatment and the sex of the treated parent was never significant (see Table S1). Coefficients are shown for control nests and for females. Significant differences $(P$-values $<0.05)$ are marked in bold

\begin{tabular}{|c|c|c|c|}
\hline Intercept & coef $=29.18 \pm 8.99$ & coef $=21.59 \pm 7.40$ & coef $=14.93 \pm 8.20$ \\
\hline Treatment (control-treated) & $\begin{array}{l}\text { coef }=-4.73 \pm 2.13 \\
F_{1,37}=4.91 \\
\boldsymbol{P}=\mathbf{0 . 0 3 3}\end{array}$ & $\begin{array}{l}\text { coef }=-3.81 \pm 1.82 \\
F_{1,35}=4.38 \\
\boldsymbol{P}=\mathbf{0 . 0 4 4}\end{array}$ & $\begin{array}{l}\text { coef }=-2.12 \pm 1.90 \\
F_{1,35}=1.25 \\
P=0.27\end{array}$ \\
\hline Sex of treated adult (females) & $\begin{array}{l}\text { coef }=-0.11 \pm 2.07 \\
F_{1,37}=0.00 \\
P=0.96\end{array}$ & $\begin{array}{l}\text { coef }=0.44 \pm 1.75 \\
F_{1,35}=0.06 \\
P=0.80\end{array}$ & $\begin{array}{l}\text { coef }=0.43 \pm 1.75 \\
F_{1,35}=0.06 \\
P=0.81\end{array}$ \\
\hline Brood size & $\begin{array}{l}\text { coef }=0.61 \pm 0.59 \\
F_{1,37}=1.06 \\
P=0.31\end{array}$ & $\begin{array}{l}\text { coef }=0.21 \pm 0.50 \\
F_{1,35}=0.18 \\
P=0.67\end{array}$ & $\begin{array}{l}\text { coef }=0.59 \pm 0.49 \\
F_{1,35}=1.45 \\
P=0.24\end{array}$ \\
\hline Days after treatment & $\begin{array}{l}\text { coef }=-4.13 \pm 1.49 \\
F_{1,37}=7.68 \\
P=\mathbf{0 . 0 0 8 7}\end{array}$ & $\begin{array}{l}\text { coef }=-3.01 \pm 1.27 \\
F_{1,35}=5.58 \\
P=\mathbf{0 . 0 2 4}\end{array}$ & $\begin{array}{l}\text { coef }=-2.21 \pm 1.31 \\
F_{1,35}=2.82 \\
P=0.10\end{array}$ \\
\hline $\begin{array}{l}\text { Feeding bouts provided by the other } \\
\text { parent }\end{array}$ & & $\begin{array}{l}\text { coef }=-0.29 \pm 0.16 \\
F_{1,35}=3.11 \\
P=0.087\end{array}$ & $\begin{array}{l}\text { coef }=-0.29 \pm 0.16 \\
F_{1,35}=3.11 \\
P=0.086\end{array}$ \\
\hline
\end{tabular}

Fig. 2 Number of feeding bouts performed by treated adults (UV-blocked/control-treated) and their partners. Error bars denote standard errors (mean \pm SE; $n=41)$. Sample sizes for each treatment are shown

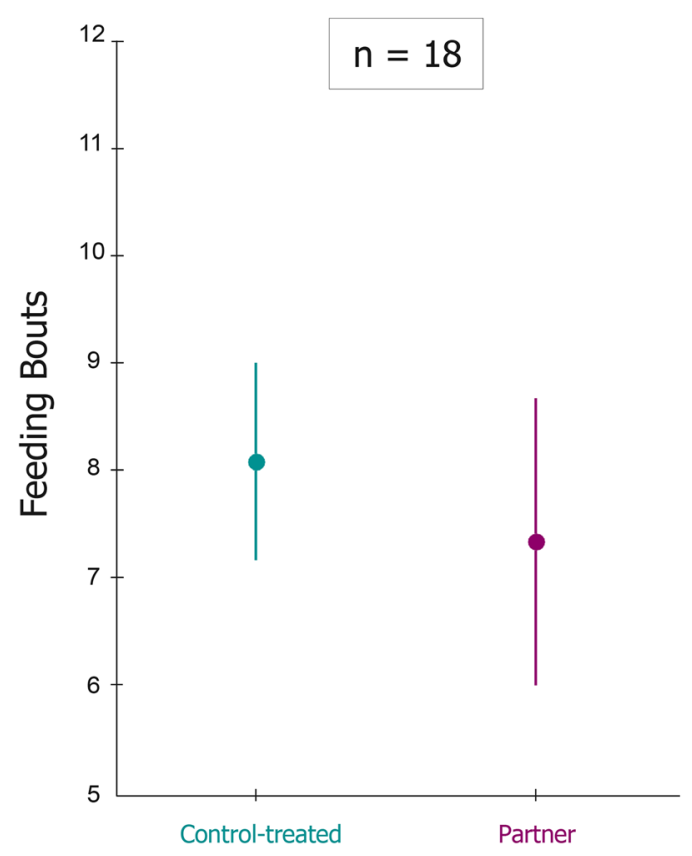

Control Nests

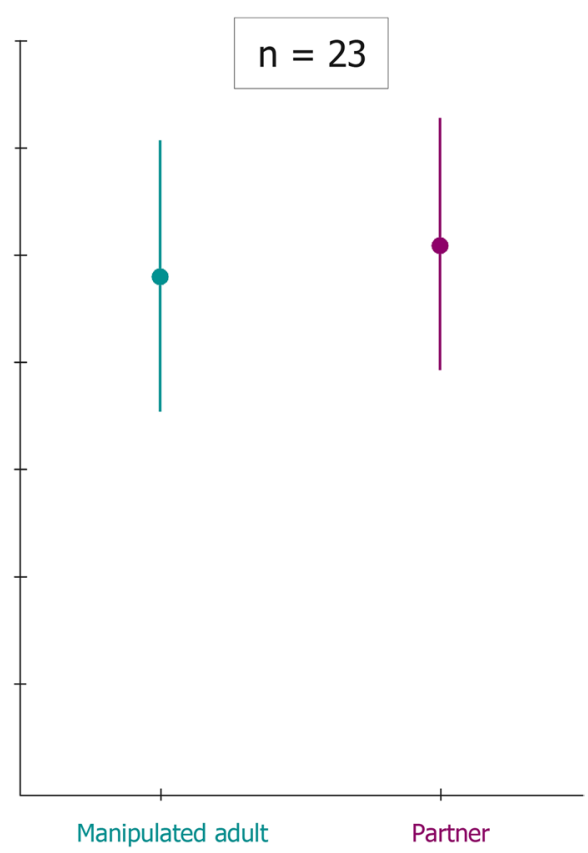

UV-Blocked Nests
Fig. 2). Days elapsed from manipulation to the video recording was negatively related with the total number of feeding bouts and with the number of the feeding bouts performed by the partner (Table 1). The sex of the treated adult did not affect the number of feeding bouts in any model (Table 1) and the interaction between treatment and sex of the treated adult was never significant (Table S1).
Prey size for both parents was smaller in UV-blocked nests than in control nests $(P=0.0091$; mean \pm SE: 2.22 \pm 0.06 , and $2.44 \pm 0.07$, respectively; Table 2 ). However, there was no treatment effect on prey size when analysed for each parent separately (Table 2), although the prey size of UV-blocked adults tended (non-significantly) to be lower than that of control-treated adults (Table 2). The interaction 
Table 2 General lineal models (LMs) showing the effect of treatment on the prey size mean per nest provided by both parents and for each one separately (i.e. the treated adult and the partner). Treated refers to UV-blocked individuals in UV-blocked nests and control-treated ones in control nests. The interaction between treatment and the sex of the treated parent was never significant (see Table S2). Coefficients are shown for control nests and for females. Significant differences $(P$-values $<0.05)$ are marked in bold
Prey size provided by both Prey size provided by the partner parents

$$
\begin{aligned}
& \text { coef }=1.16 \pm 0.65 \\
& \text { coef }=0.12 \pm 0.15 \\
& F_{1,34}=0.64 \\
& P=0.43 \\
& \text { coef }=-0.11 \pm 0.13 \\
& F_{1,34}=0.69 \\
& P=0.41 \\
& \text { coef }=0.05 \pm 0.04 \\
& F_{1,34}=1.92 \\
& P=0.18 \\
& \text { coef }=0.03 \pm 0.09 \\
& F_{1,34}=0.09 \\
& P=0.76 \\
& \text { coef }=0.24 \pm 0.19 \\
& F_{1,34}=1.58 \\
& P=0.22
\end{aligned}
$$

Prey size provided by the treated adult between treatment and sex of the treated adult was not significant (see Table S2).

The effect of UV manipulation on the number of feeding bouts of treated parents and their partners and on prey size

\begin{tabular}{|c|c|c|c|}
\hline & Begging intensity to both parents & Begging intensity to the partner & $\begin{array}{l}\text { Begging intensity to } \\
\text { the treated adult }\end{array}$ \\
\hline Intercept & $\operatorname{coef}=1.31 \pm 0.58$ & coef $=0.96 \pm 0.43$ & coef $=0.19 \pm 0.48$ \\
\hline Treatment (control-treated) & $\begin{array}{l}\text { coef }=0.11 \pm 0.14 \\
F_{1,36.5}=0.67 \\
P=0.42\end{array}$ & $\begin{array}{l}\text { coef }=0.01 \pm 0.11 \\
F_{1,33.4}=0.01 \\
P=0.92\end{array}$ & $\begin{array}{l}\text { coef }=0.11 \pm 0.11 \\
F_{1,34.8}=1.00 \\
P=0.33\end{array}$ \\
\hline Sex of treated adult (females) & $\begin{array}{l}\text { coef }=-0.06 \pm 0.13 \\
F_{1,36.2}=0.22 \\
P=0.64\end{array}$ & $\begin{array}{l}\text { coef }=-0.18 \pm 0.10 \\
F_{1,32.4}=3.27 \\
P=0.080\end{array}$ & $\begin{array}{l}\text { coef }=-0.18 \pm 0.11 \\
F_{1,34.1}=2.73 \\
P=0.11\end{array}$ \\
\hline Sex of nestling (females) & $\begin{array}{l}\text { coef }=-0.02 \pm 0.06 \\
F_{1,326}=0.15 \\
P=0.70\end{array}$ & $\begin{array}{l}\text { coef }=-0.01 \pm 0.07 \\
F_{1,321}=0.05 \\
P=0.83\end{array}$ & $\begin{array}{l}\text { coef }=-0.01 \pm 0.06 \\
F_{1,316}=0.01 \\
P=0.93\end{array}$ \\
\hline Brood size & $\begin{array}{l}\text { coef }=-0.09 \pm 0.04 \\
F_{1,38.9}=4.90 \\
\boldsymbol{P}=\mathbf{0 . 0 3 3}\end{array}$ & $\begin{array}{l}\text { coef }=-0.07 \pm 0.03 \\
F_{1,37.5}=4.94 \\
\boldsymbol{P}=\mathbf{0 . 0 3 2}\end{array}$ & $\begin{array}{l}\text { coef }=-0.007 \pm 0.03 \\
F_{1,39.1}=0.04 \\
P=0.84\end{array}$ \\
\hline Days after treatment & $\begin{array}{l}\text { coef }=0.13 \pm 0.09 \\
F_{1,35.5}=1.94 \\
P=0.17\end{array}$ & $\begin{array}{l}\text { coef }=0.03 \pm 0.07 \\
F_{1,32.4}=0.21 \\
P=0.65\end{array}$ & $\begin{array}{l}\text { coef }=0.10 \pm 0.08 \\
F_{1,33.9}=1.85 \\
P=0.18\end{array}$ \\
\hline Begging intensity to the other parent & & $\begin{array}{l}\text { coef }=0.64 \pm 0.05 \\
F_{1,316}=184.15 \\
P<\mathbf{0 . 0 0 0 1}\end{array}$ & $\begin{array}{l}\text { coef }=0.55 \pm 0.04 \\
F_{1,332}=179.19 \\
\boldsymbol{P}<\mathbf{0 . 0 0 0 1}\end{array}$ \\
\hline
\end{tabular}
remains qualitatively similar if monoparental nests are also included (Tables S5 and S6).

Table 3 General mixed models (GLMMs) showing the effect of treatment on the mean begging intensity of nestlings directed to both parents and to each one separately (i.e. the treated adult and the partner). Treated refers to UV-blocked individuals in UV-blocked nests

\section{Begging intensity and nestling fitness parameters}

There was no treatment effect on the average begging intensity of individual nestlings, neither directed to both parents (Table 3) nor when analysed for each parent separately (Table 3; Fig. 3). Begging intensity to both parents and to the

and control-treated ones in control nests. The interaction between treatment and the sex of the treated parent was never significant (see Table S3). Coefficients are shown for control nests and for females. Significant differences $(P$-values $<0.05)$ are marked in bold 
Fig. 3 Mean begging intensity of nestlings to treated adults (UV-blocked/control-treated) and their partners. Error bars denote standard errors (mean \pm SE; $n=40)$. Sample sizes for each treatment are shown

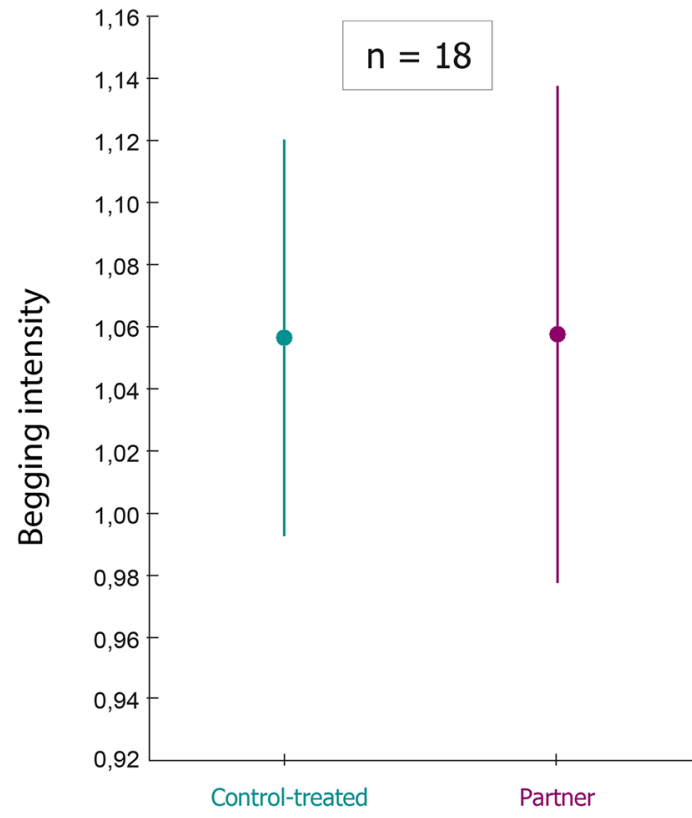

Control Nests

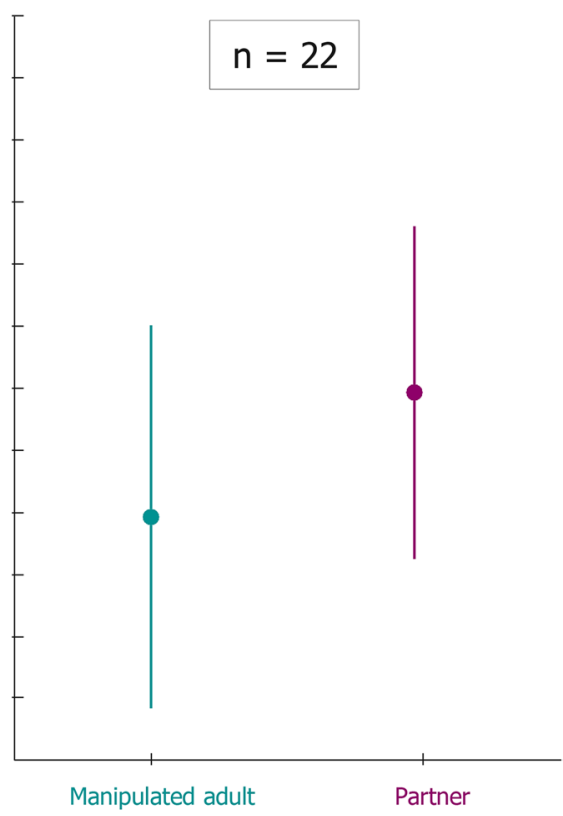

UV-Blocked Nests
Table 4 General mixed model (GLMM) and generalized linear model (GLZ) with Poisson distribution showing the effects of treatment, respectively, on nestling body mass and fledging success (i.e. number of offspring that fledged). Coefficients are shown for control nests and for females. The interaction between treatment and the sex of the treated parent was never significant (see Table S4). Significant differences $(P$-values $<0.05)$ are marked in bold

\begin{tabular}{lll}
\hline & $\begin{array}{l}\text { Nestling body mass } \\
(\mathrm{g})\end{array}$ & Fledging success \\
\hline Intercept & coef $=11.55 \pm 0.53$ & coef $=0.96 \pm 0.48$ \\
Treatment & coef $=-0.04 \pm 0.14$ & coef $=0.02 \pm 0.12$ \\
(control-treated) & $F_{1,43.2}=0.10$ & $\chi^{2}=0.03$ \\
& $P=0.76$ & $P=0.87$ \\
Sex of treated adult & coef $=0.01 \pm 0.13$ & coef $=-0.02 \pm 0.11$ \\
(females) & $F_{1,42.7}=0.00$ & $\chi^{2}=0.02$ \\
& $P=0.96$ & $P=0.88$ \\
Sex of nestling & coef $=-0.44 \pm 0.06$ & \\
(females) & $F_{1,362}=65.64$ & \\
& $\boldsymbol{P}<\mathbf{0 . 0 0 0 1}$ & \\
Brood size & coef $=-0.15 \pm 0.04$ & coef $=0.13 \pm 0.03$ \\
& $F_{1,44.8}=14.73$ & $\chi^{2}=17.02$ \\
& $\boldsymbol{P}=\mathbf{0 . 0 0 0 4}$ & $\boldsymbol{P}<\mathbf{0 . 0 0 0 1}$ \\
Days after treatment & coef $=0.06 \pm 0.08$ & coef $=-0.0004 \pm 0.08$ \\
& $F_{1,42}=0.49$ & $\chi^{2}=0.00$ \\
& $P=0.49$ & $P=0.99$ \\
\hline
\end{tabular}

partner was significantly lower in larger broods (Table 3 ). The interaction between treatment and sex of the treated adult was not significant (Table S3).

No effect of treatment was found on nestling body mass (Table 4). Male nestlings were significantly heavier than female nestlings (Table 4). Brood size was negatively related to nestling body mass (Table 4). Finally, no effect of treatment was found on fledging success (Table 4). The interaction between treatment and sex of the treated adult was not significant (Table S4).

The effect of UV manipulation on the begging intensity to treated parents and their partners and on nestling body mass and fledging success remains qualitatively similar if monoparental nests are also included (Tables S7 and S8).

\section{Discussion}

In this experimental study, we investigated the role of UV/ yellow colouration in multiple intra-family contexts. We hypothesized that UV colouration could be perceived by the partner, who may co-adjust their contribution to parental care accordingly, and by nestlings affecting their begging behaviour (i.e. the amount of food they demand). We indeed found that the partners of UV-blocked individuals increased the number of feeding bouts, providing experimental evidence that UV/yellow breast colouration acts as a signal that affects parental care strategies in blue tits. However, despite this, we found no evidence that nestlings responded to this (manipulated) parental signal. Below, we discuss the potential causes and consequences of this discrepancy.

\section{Parental behaviour: feeding bouts and prey size}

We found that the parental investment here measured in terms of the total number of feeding bouts - thus considering both parents - was significantly higher in nests with a 
UV-blocked adult. When we analysed the pair members separately, we found that the observed increase was due to the fact that partners of UV-blocked adults enhanced the number of feeding bouts. We interpret that the reduction in UV/yellow reflectance of breast plumage triggered a compensatory response by the partner, who took over a greater proportion of care given the apparent lower-quality partner, as found in previous studies in this and other species (Gowaty et al. 2003: Bluhm and Gowaty 2004; Bolund et al. 2009; Limbourg et al. 2013a). Compensatory responses are probably more advantageous at late stages of offspring development, when most of the parental investment has already been performed and when the extra-investment could in addition be of short duration. While a manipulation of the UV colour at very early stages of reproduction, i.e. during pair-bonding, could induce a divorce to avoid a compensatory investment by exchanging the manipulated partner in due time. The effect of treatment on the feeding bouts of partners was irrespective of the sex of the treated adult, suggesting that this trait functions as an ornament in both sexes. Previous studies on the same species showed that males and females responded differently when paired with non-attractive mates with experimentally reduced UV/blue crown colouration; blue tit females decreased their feeding rates when paired with UV-blocked males (Limbourg et al. 2004), whereas males increased their feeding rates when paired with UVblocked females (Limbourg et al. 2013a). The causes of this difference remain as yet unresolved, but could be due to the fact that these are different ornaments with potentially different role (i.e. crown feathers (Limbourg et al. 2004, 2013a, b) versus breast feathers (this study)).

For breast feathers, previous studies in blue tits have focused on carotenoid-based colouration in adults showing that it reflects aspects of individual quality (e.g. del Cerro et al. 2010; García-Navas et al. 2012; Midamegbe et al. 2013). Thus, further studies are necessary to experimentally demonstrate the link between UV reflectance of yellow breast feathers and condition in adults. Yet, given the evidence from studies in nestlings, by reducing trait expression, we presumably mimicked the appearance of low-quality individuals (Johnsen et al. 2003; Jacot and Kempenaers 2007; Janas et al. 2018; Morales and Velando 2018; see also Szigeti et al. 2007; Henderson et al. 2013; Midamegbe et al. 2013; Badás et al. 2018 in other UV coloured feather tracts in adults). It also has to be noted that UV-blocking represents an artificial manipulation creating a phenotype that does not exist, as one trait component (here UV) is selectively modified (Hauber et al. 2015; Lahti and Ardia 2016; Stoddard et al. 2019), even though with respect to reflectance, our manipulation remained within the natural range (Fig. S1). Furthermore, we cannot exclude the possibility that UV-blocked adults could be perceived as a bearer of an "enhanced" signal, as it has been shown that
UV reflectance is negatively related to carotenoid content (Jacot et al. 2010). However, we consider this interpretation less likely given our previous results on UV/yellow in blue tit nestlings (Morales and Velando 2018; GarcíaCampa et al. 2021). Another alternative explanation is that the manipulated adults would resemble an extreme case of "soiling" which has been found to reduce the UV reflectance (Surmacki et al. 2011); yet, here it remains unclear which behavioural response we should expect.

As expected, UV-blocked adults did not change their own rate of nestling provisioning. Indeed, the condition or quality of the UV-blocked adult had not changed after manipulation but only the signal expression. The UV-blocked adult might only change its behaviour if it self-perceives the manipulated signal directly or if it adjusts its behaviour because it responds indirectly to the changes in its partner's behaviour (Burley 1986, 1988; Sanz 2001; Cline et al. 2016), for which we did not have evidence. The latter is in contrast to a recent hypothesis that partners co-adjust their investment based on behavioural traits - by checking each other's performance during feeding visits, which should result in an alternated sequence of feeding visits (Hinde 2006; Johnstone et al. 2014; Griffioen et al. 2019; Iserbyt et al. 2019). The fact that our manipulation did induce a unilateral change in parental provisioning rather suggests that partners respond to the mate's signal, and not to its behaviour. However, it is also possible that partners responded to both mate's cues combined. Even though this remains speculative, we propose that partners could rate their mate's parental effort differently after manipulation, as they expect a lower contribution of care by their mate - based on the (manipulated) signal. Thus, the partner perceives that the UV-blocked adult is performing relatively better than expected given its (manipulated) low quality. In other words, as its signal but not its feeding rate has changed, this could trigger a positive response in the partner.

Our results also show that in nests with an UV-blocked adult both parents provided smaller prey items than control nests. One possibility is that the increase of total feeding rates in UV-blocked nests would compromise the provisioning over larger prey items. However, this would only apply to the parents that increased feeding rates (i.e. the partners of UV-blocked individuals). A non-excluding possibility is that UV-blocked adults relaxed their foraging effort due to the increase in investment of their partners.

\section{Offspring: begging, growth, and survival}

As signals can be perceived by all family members, we expected that the UV manipulation in adults could affect parent-offspring interactions. Indeed, parental signals have been shown to affect offspring behaviour in other species, although evidence is still scarce (Tinbergen and 
Perdeck 1950; Velando et al. 2013; reviewed by Morales and Velando 2013). Moreover, blue tit nestlings have been shown to respond to their siblings' UV/yellow colouration (Morales and Velando 2018), revealing that the signal can be perceived, even inside a cavity/their nest box. However, we did not find differences in nestling behaviour according to parental treatment. This could be due to the fact that offspring - contrary to adults - do not respond to the signal but to other parental cues, such as the number of feeding bouts, prey-testings, or to adult's feeding calls. We argue that the signal might not be relevant for the offspring, who may only have to distinguish between parents, and then associate the respective phenotype with a given parental quality. However, adults may use this signal before the rearing period when direct information on adult provisioning is not available yet. We cannot exclude, however, that the offspring relied on other parental signals (e.g. UV/white and UV/blue colouration) not considered here, and future work is needed to test this possibility. Also, we cannot discard that the lack of response in the offspring could be due to the fact that we only observed 30 min of behaviour, which may not be enough to detect differences in nestling begging, or to the fact that we recorded the videos (on average) 3.5 days after parental manipulation. However, the very detailed analysis of the videos and hence the high effort hindered a longer time frame for the observations of offspring behaviour, and our time frame is comparable to that of a previous study focusing on parental behaviour in blue tits (Griffioen et al. 2019).

We expected that nestlings raised in UV-blocked nests should gain more body mass and survive better than those in control nests due to an overall increased parental investment. However, despite the treatment effect on parental feeding rates, we did not find effects on nestling body mass nor on fledging success. One possible explanation is that our manipulation was too late, so that nestlings were already nearly fully developed and growth differences more difficult to detect, given also the comparatively small sample sizes. Another possibility could be that the time between manipulation and mass measurement was too short (on average 3.51 days $\pm 0.71 \mathrm{SD}$; see "Material and methods"). So it is possible that body mass differences could have been detected later, at fledging. Nonetheless, the previous explanations seem not likely given that, previously, the blocking of UV/yellow nestling colour resulted in changes in brood behaviour and body mass just after $24 \mathrm{~h}$ (Morales and Velando 2018). Finally, in UV-blocked nests, parents increased their feeding bouts but reduced prey size, so overall, the energetic intake might have been equal, causing the lack of differences between treatments in nestling body mass.

\section{Conclusions}

Our study shows that structural UV/yellow colouration of breast feathers in adult blue tits affects parental provisioning strategies in both sexes. We observed that adults responded to the partner's manipulated plumage trait and not to its behaviour (i.e. number of feeding bouts) in order to adjust parental effort. This supports the concept of flexible parenting, with UV/yellow colouration of blue tit adults revealing aspects of parental capacity and parents adjusting their investment based on this signal. The latter was not found for offspring; nestlings did not respond to the manipulated signal of one of their parents. We hypothesize that they should rather respond to their parents' behaviour (feeding bouts, prey-testings, or feeding calls). This remains as yet somewhat speculative, given also our relatively small sample size and to the fact that we only observed behaviour during 30 $\min$.

We encourage future studies incorporating the manipulation of carotenoid-based signals to understand how both components (UV and carotenoids) simultaneously affect intra-family communication. Also, further studies should explore whether observed changes in parental investment, or the willingness for compensatory investment might have long-term effects for pair bond duration or parental investment in the subsequent breeding seasons. As of yet, too little attention has thus far been paid to how offspring could optimally fine-tune their behaviour to parental rearing capacity.

Supplementary Information The online version contains supplementary material available at https://doi.org/10.1007/s00265-022-03145-1.

Acknowledgements We thank Carmen Sáez-Royuela for the help during video observations and Emilio García-Juárez for molecular sexing. We are also grateful to Daniel Díaz and Alejandra Mira (from the Centro de Gestión del Parque Regional de la Cuenca Alta del Río Manzanares) for logistic support. We also thank the anonymous reviewers and the Associate Editor Stephen Pruett-Jones whose comments and suggestions helped improve and clarify this manuscript.

Funding Open Access funding provided thanks to the CRUE-CSIC agreement with Springer Nature. Grants CGL2016-79390-P and PID2019-106032GB-I00 (to JM) funded by MCIN/AEI/ https://doi.org/ $10.13039 / 501100011033$ and by "ERDF A way of making Europe". JG-C was supported by Grant BES-2017-079750 and JM by a Ramón y Cajal contract RYC-2014-15145 funded by MCIN/AEI/ https://doi.org/ $10.13039 / 501100011033$ and "ESF Investing in your future".

Data availability https://doi.org/10.6084/m9.figshare.13359926.v1

\section{Declarations}

Ethics approval The study was approved by the Ethical Committees of the Spanish Research Council and the Consejería de Medio Ambiente, Administración Local y Ordenación del Territorio, Comunidad de Madrid (PROEX 237/17). The experiment was performed in accordance with the Guidelines for the Treatment of Animals in 
Behavioural Research and Teaching from the Association for the Study of Animal Behaviour/Animal Behaviour Society (ASAB/ABS) (2012). The research was conducted with the permission (reference: 10/014163.9/11) from Dirección General de Medio Ambiente y Sostenibilidad, Consejería de Medio Ambiente y Ordenación del Territorio, Comunidad de Madrid, Spain and was performed in accordance with the Spanish law.

Conflict of interest The authors declare no competing interests.

Open Access This article is licensed under a Creative Commons Attribution 4.0 International License, which permits use, sharing, adaptation, distribution and reproduction in any medium or format, as long as you give appropriate credit to the original author(s) and the source, provide a link to the Creative Commons licence, and indicate if changes were made. The images or other third party material in this article are included in the article's Creative Commons licence, unless indicated otherwise in a credit line to the material. If material is not included in the article's Creative Commons licence and your intended use is not permitted by statutory regulation or exceeds the permitted use, you will need to obtain permission directly from the copyright holder. To view a copy of this licence, visit http://creativecommons.org/licenses/by/4.0/.

\section{References}

Avilés JM, Soler JJ, Pérez-Contreras T (2006) Dark nests and egg colour in birds: a possible functional role of ultraviolet reflectance in egg detectability. Proc R Soc Lond B 273:2821-2829. https:// doi.org/10.1098/rspb.2006.3674

Badás EP, Martínez J, Rivero-de Aguilar J, Ponce C, Stevens M, Merino S (2018) Colour change in a structural ornament is related to individual quality, parasites and mating patterns in the blue tit. Sci Nat 105:17. https://doi.org/10.1007/s00114-018-1539-z

Bluhm CK, Gowaty PA (2004) Reproductive compensation for offspring viability deficits by female mallards, Anas platyrhynchos. Anim Behav 68:985-992. https://doi.org/10.1016/j.anbehav.2004. 01.012

Bolund E, Schielzeth H, Forstmeier W (2009) Compensatory investment in zebra finches: females lay larger eggs when paired to sexually unattractive males. Proc R Soc Lond B 276:707-715. https://doi.org/10.1098/rspb.2008.1251

Bradbury JW, Vehrencamp SL (2011) Principles of animal communication, 2nd edn. Sinauer Associates, Sunderland, MA

Burley N (1986) Sexual selection for aesthetic traits in species with biparental care. Am Nat 127:415-445. https://doi.org/10.1086/ 284493

Burley N (1988) The differential-allocation hypothesis: an experimental test. Am Nat 132:611-628. https://doi.org/10.1086/284877

Capilla-Lasheras P, Dominoni DM, Babayan SA, O’Shaughnessy PJ, Mladenova M, Woodford L, Pollock CJ, Barr T, Baldini F, Helm B (2017) Elevated immune gene expression is associated with poor reproductive success of urban blue tits. Front Ecol Evol 5:64. https://doi.org/10.3389/fevo.2017.00064

Cline MH, Hatt JL, Conroy MJ, Cooper RJ (2016) Experimental evidence for a phenotypic trait as an age-dependent intrasexual social signal between familiar individuals. Anim Behav 111:319-327. https://doi.org/10.1016/j.anbehav.2015.11.004

Danchin É, Giraldeau LA, Valone TJ, Wagner RH (2004) Public information: from noisy neighbors to cultural evolution. Science 305:487-491. https://doi.org/10.1126/science.1098254

del Cerro S, Merino S, Martínez-de la Puente J, Lobato E, Ruiz-deCastañeda R, Rivero-de Aguilar J, Martínez J, Morales J, Tomás
G, Moreno J (2010) Carotenoid-based plumage colouration is associated with blood parasite richness and stress protein levels in blue tits (Cyanistes caeruleus). Oecologia 162:825-835

Delhey K, Peters A, Johnsen A, Kempenaers B (2006) Seasonal changes in blue tit crown color: do they signal individual quality? Behav Ecol 17:790-798. https://doi.org/10.1093/beheco/ $\operatorname{arl} 1012$

Doutrelant C, Fargevieille A, Grégoire A (2020) Evolution of female coloration: what have we learned from birds in general and blue tits in particular. Adv Stud Behav 52:123-202. https://doi.org/10. 1016/bs.asb.2020.03.001

Doutrelant C, Grégoire A, Grnac N, Gomez D, Lambrechts MM, Perret $\mathrm{P}$ (2008) Female coloration indicates female reproductive capacity in blue tits. J Evol Biol 21:226-233. https://doi.org/10.1111/j. 1420-9101.2007.01451.x

Doutrelant C, Grégoire A, Midamegbe A, Lambrechts M, Perret P (2012) Female plumage coloration is sensitive to the cost of reproduction. An experiment in blue tits. J Anim Ecol 81:87-96. https://doi.org/10.1111/j.1365-2656.2011.01889.x

Ferns PN, Hinsley SA (2008) Carotenoid plumage hue and chroma signal different aspects of individual and habitat quality in tits. Ibis 150:152-159

Ferrer ES, García-Navas V, Bueno-Enciso J, Sanz JJ, Ortego J (2015) Multiple sexual ornaments signal heterozygosity in male blue tits. Biol J Linn Soc, 115(2), 362-375. https://doi.org/10.1111/ bij. 12513

Folstad I, Karter AJ (1992) Parasites, bright males, and the immunocompetence handicap. Am Nat 139:603-622. https://doi.org/ $10.1086 / 285346$

Galván I, Amo L, Sanz JJ (2008) Ultraviolet-blue reflectance of some nestling plumage patches mediates parental favouritism in great tits Parus major. J Avian Biol 39:277-282. https://doi.org/10. 1111/j.0908-8857.2008.04273.x

García-Campa J, Müller W, Hernández-Correas E, Morales J (2021) The early maternal environment shapes the parental response to offspring UV ornamentation. Sci Rep 11:20808. https://doi.org/ 10.1038/s41598-021-00251-4

García-Navas V, Ferrer ES, Sanz JJ (2012) Plumage yellowness predicts foraging ability in the blue tit Cyanistes caeruleus. Biol J Linn Soc 106:418-429

Gowaty PA (2008) Reproductive compensation. J Evol Biol. 21:11891200. https://doi.org/10.1111/j.1420-9101.2008.01559.x

Gowaty PA, Anderson WW, Bluhm CK, Drickamer LC, Kim YK, Moore AJ (2007) The hypothesis of reproductive compensation and its assumptions about mate preferences and offspring viability. Proc Natl Acad Sci USA 104:15023-15027. https://doi.org/10. 1073/pnas.0706622104

Gowaty PA, Drickamer LC, Schmid-Holmes S (2003) Male house mice produce fewer offspring with lower viability and poorer performance when mated with females they do not prefer. Anim Behav 65:95-103. https://doi.org/10.1006/anbe.2002.2026

Griffioen M, Iserbyt A, Müller W (2019) Handicapping males does not affect their rate of parental provisioning, but impinges on their partners' turn taking behavior. Front Ecol Evol 7:347. https://doi. org/10.3389/fevo.2019.00347

Hakkarainen H, Koivunen V, Korpimäki E (1997) Reproductive success and parental effort of Tengmalm's owls: effects of spatial and temporal variation in habitat quality. Ecoscience 4:35-42. https:// doi.org/10.1080/11956860.1997.11682374

Hamilton WD, Zuk M (1982) Heritable true fitness and bright birds: a role for parasites? Science 218:384-387. https://doi.org/10.1126/ science. 7123238

Harris WE, Uller T (2009) Reproductive investment when mate quality varies: differential allocation versus reproductive compensation. Philos Trans R Soc B 364:1039-1048. https://doi.org/10.1098/ rstb.2008.0299 
Hauber ME, Tong L, Bán M, Croston R, Grim T, Waterhouse GIN, Shawkey MD, Barron C, Moskát C (2015) The value of artificial stimuli in behavioral research: making the case for egg rejection studies in avian brood parasitism. Ethology 121:521-528. https:// doi.org/10.1111/eth.12359

Henderson LJ, Heidinger BJ, Evans NP, Arnold KE (2013) Ultraviolet crown coloration in female blue tits predicts reproductive success and baseline corticosterone. Behav Ecol 24:1299-1305. https:// doi.org/10.1093/beheco/art066

Hidalgo-Garcia S (2006) The carotenoid-based plumage coloration of adult blue tits Cyanistes caeruleus correlates with the health status of their brood. Ibis 148:727-734

Hinde CA (2006) Negotiation over offspring care? - A positive response to partner-provisioning rate in great tits. Behav Ecol 17:6-12. https://doi.org/10.1093/beheco/ari092

Hunt S, Kilner RM, Langmore NE, Bennett ATD (2003) Conspicuous, ultraviolet-rich mouth colours in begging chicks. Proc R Soc Lond B 270:S25-S28. https://doi.org/10.1098/rsbl.2003.0009

Iserbyt A, Griffioen M, Eens M, Müller W (2019) Enduring rules of care within pairs - how blue tit parents resume provisioning behaviour after experimental disturbance. Sci Rep 9:2776. https:// doi.org/10.1038/s41598-019-39139-9

Jacot A, Kempenaers B (2007) Effects of nestling condition on UV plumage traits in blue tits: an experimental approach. Behav Ecol 1:34-40. https://doi.org/10.1093/beheco/arl054

Jacot A, Romero-Diaz C, Tschirren B, Richner H, Fitze PS (2010) Dissecting carotenoid from structural components of carotenoidbased coloration: a field experiment with great tits (Parus major). Am Nat 176:55-62. https://doi.org/10.1086/653000

Janas K, Lutyk D, Sudyka J, Dubiec A, Gustafsson L, Cichoń M, Drobniak S (2020) Carotenoid-based coloration correlates with the hatching date of blue tit Cyanistes caeruleus nestlings. Ibis 162:645-654

Janas K, Podmokła E, Lutyk D, Dubiec A, Gustafsson L, Cichoń M, Drobniak S (2018) Influence of haemosporidian infection status on structural and carotenoid-based colouration in the blue tit Cyanistes caeruleus. J Avian Biol 2018:e01840. https://doi.org/ 10.1111/jav.01840

Johnsen A, Delhey K, Andersson S, Kempenaers B (2003) Plumage colour in nestling blue tits: sexual dichromatism, condition dependence and genetic effects. Proc R Soc Lond B 270:12631270. https://doi.org/10.1098/rspb.2003.2375

Johnsen A, Delhey K, Schlicht E, Peters A, Kempenaers B (2005) Male sexual attractiveness and parental effort in blue tits: a test of the differential allocation hypothesis. Anim Behav 70:877-888. https://doi.org/10.1016/j.anbehav.2005.01.005

Johnstone RA, Manica A, Fayet AL, Stoddard MC, Rodriguez-Girones MA, Hinde CA (2014) Reciprocity and conditional cooperation between great tit parents. Behav Ecol 25:216-222. https://doi.org/ 10.1093/beheco/art109

Kokko H (1998) Should advertising parental care be honest? Proc R Soc Lond B 265:1871-1878. https://doi.org/10.1098/rspb.1998. 0515

Kölliker M, Richner H, Werner I, Heeb P (1998) Begging signals and biparental care: nestling choice between parental feeding locations. Anim Behav 55:215-222. https://doi.org/10.1006/anbe. 1997.0571

Korsten P, Limbourg T, Lessells KM, Komdeur J (2007) Effectiveness of a commonly-used technique for experimentally reducing plumage UV reflectance. J Avian Biol 38:399-403. https://doi.org/10. 1111/j.2007.0908-8857.03963.x

Lahti DC, Ardia DR (2016) Shedding light on bird egg color: pigment as parasol and the dark car effect. Am Nat 187:547-563. https:// doi.org/10.1086/685780

Limbourg T, Mateman AC, Andersson S, Lessells CM (2004) Female blue tits adjust parental effort to manipulated male UV attractiveness. Proc R Soc Lond B 271:1903-1908. https://doi. org/10.1098/rspb.2004.2825

Limbourg T, Mateman AC, Lessells CM (2013) Parental care and UV coloration in blue tits: opposite correlations in males and females between provisioning rate and mate's coloration. J Avian Biol 44:017-026. https://doi.org/10.1111/j.1600-048X.2012. 05575.x

Limbourg T, Mateman AC, Lessells CM (2013) Opposite differential allocation by males and females of the same species. Biol Lett 9:20120835. https://doi.org/10.1098/rsbl.2012.0835

Lucass C, Iserbyt A, Eens M, Müller W (2016) Structural (UV) and carotenoid-based plumage coloration - signals for parental investment? Ecol Evol 6:3269-3279. https://doi.org/10.1002/ ece 3.2107

Matysiokova B, Remeš V (2010) Incubation feeding and nest attentiveness in a socially monogamous songbird: role of feather colouration, territory quality and ambient environment. Ethology 116:596-607

Midamegbe A, Grégoire A, Staszewski V, Perret P, Lambrechts MM, Boulinier T, Doutrelant C (2013) Female blue tits with brighter yellow chests transfer more carotenoids to their eggs after an immune challenge. Oecologia 173:387-397. https://doi.org/10. 1007/s00442-013-2617-8

Morales J, Alonso-Álvarez C, Pérez C, Torres R, Serafino E, Velando A (2009) Families on the spot: sexual signals influence parentoffspring interactions. Proc R Soc Lond B 276:2477-2483. https://doi.org/10.1098/rspb.2008.1942

Morales J, Cuervo JJ, Moreno J, Soler JJ (2019) Juvenile plumage whiteness is associated with the evolution of clutch size in passerines. Behav Ecol 30:1106-1112. https://doi.org/10.1093/ beheco/arz058

Morales J, Torres R, Velando A (2012) Safe betting: males help dull females only when they raise high-quality offspring. Behav Ecol Sociobiol 66:135-143. https://doi.org/10.1007/ s00265-011-1261-8

Morales J, Velando A (2013) Signals in family conflicts. Anim Behav 86:11-16. https://doi.org/10.1016/j.anbehav.2013.04.001

Morales J, Velando A (2018) Coloration of chicks modulates costly interactions among family members. Behav Ecol 29:894-903. https://doi.org/10.1093/beheco/ary057

Ots I, Hõrak P (1998) Health impact of blood parasite in breeding great tits. Oecologia 116:441-448. https://doi.org/10.1007/ s004420050608

Pagani-Núñez E, Senar JC (2014) Are colorful males of great tits Parus major better parents? Parental investment is a matter of quality. Acta Oecol 55:23-28

Ratikainen II, Kokko H (2010) Differential allocation and compensation: who deserves the silver spoon? Behav Ecol 21:195-200. https://doi.org/10.1093/beheco/arp168

Sanz JJ (2001) Experimentally reduced male attractiveness increases parental care in the pied flycatcher Ficedula hypoleuca. Behav Ecol 12:171-176. https://doi.org/10.1093/beheco/12.2.171

Savage JL, Hinde CA (2019) What can we quantify about carer behavior? Front Ecol Evol 7:418. https://doi.org/10.3389/fevo. 2019.00418

Schwagmeyer PL, Mock DW (2008) Parental provisioning and offspring fitness: size matters. Anim Behav 75:291-298. https:// doi.org/10.1016/j.anbehav.2007.05.023

Senar JC, Figuerola J, Pascual J (2002) Brighter yellow blue tits make better parents. Proc R Soc Lond B 269:257-261

Senar JC, Quesada J (2006) Absolute and relative signals: a comparison between melanin-and carotenoid-based patches. Behaviour 143:589-595. https://doi.org/10.1163/156853906776759484

Shawkey MD, Hill GE (2005) Carotenoids need structural colours to shine. Biol Lett 1:121-124. https://doi.org/10.1098/rsbl.2004. 0289 
Sheldon BC (2000) Differential allocation: tests, mechanisms and implications. Trends Ecol Evol 15:397-402. https://doi.org/10. 1016/S0169-5347(00)01953-4

Smiseth PT, Andrews C, Brown E, Prentice PM (2010) Chemical stimuli from parents trigger larval begging in burying beetles. Behav Ecol 21:526-531. https://doi.org/10.1093/beheco/arq019

Soler JJ, Navarro C, Contreras TP, Avilés JM, Cuervo JJ (2008) Sexually selected egg coloration in spotless starlings. Am Nat 171:183-194. https://doi.org/10.1086/524958

Stearns SC (1992) The evolution of life histories. Oxford University Press, Oxford, UK

Steiger S, Franz R, Eggert AK, Müller JK (2008) The Coolidge effect, individual recognition and selection for distinctive cuticular signatures in a burying beetle. Proc R Soc Lond B 275:1831-1838. https://doi.org/10.1098/rspb.2008.0375

Stoddard MC, Miller AE, Eyster HN, Akkaynak D (2019) I see your false colours: how artificial stimuli appear to different animal viewers. Interface Focus 9:20180053. https://doi.org/10.1098/ rsfs.2018.0053

Surmacki A, Liu M, Mercadante A, Hill GE (2011) Effect of feather abrasion on structural coloration in male eastern bluebirds Sialia sialis. J Avian Biol 42:514-521. https://doi.org/10.1111/j.1600048X.2011.05503.X

Szigeti B, Török J, Hegyi G, Rosivall B, Hargitai R, Szöllösi E, Michl G (2007) Egg quality and parental ornamentation in the blue tit Parus caeruleus. J Avian Biol 38:105-112. https://doi.org/10. 1111/j.2007.0908-8857.03769.x

Tanner M, Richner H (2008) Ultraviolet reflectance of plumage for parent-offspring communication in the great tit (Parus major). Beh Ecol 19:369-373. https://doi.org/10.1093/beheco/arm142

Tinbergen N, Perdeck AC (1950) On the stimulus situation releasing the begging response in the newly hatched herring gull chick (Larus Argentatus Argentatus Pont.). Behaviour 3:1-39. https:// doi.org/10.1163/156853951x00197

Trivers R (1972) Parental investment and sexual selection. In: Campbell B (ed) Sexual selection and the descent of man, 1871-1971. Aldine de Gruyter, Chicago, IL, pp 136-179
Vedder O, Korsten P, Magrath MJL, Komdeur J (2008) Ultraviolet plumage does not signal social status in free-living blue tits; an experimental test. Behav Ecol 19:410-416. https://doi.org/10. 1093/beheco/arm146

Velando A, Beamonte-Barrientos R, Torres R (2006) Pigment-based skin colour in the blue-footed booby: an honest signal of current condition used by females to adjust reproductive investment. Oecologia 149:535-542. https://doi.org/10.1007/s00442-006-0457-5

Velando A, Kim S, Noguera JC (2013) Begging response of gull chicks to the red spot on the parental bill. Anim Behav 85:1359-1366. https://doi.org/10.1016/j.anbehav.2013.03.027

Velando A, Torres R, Espinosa I (2005) Male coloration and chick condition in blue-footed booby: a cross-fostering experiment. Behav Ecol Sociobiol 58:175-180. https://doi.org/10.1007/ s00265-005-0911-0

Węgrzyn E, Leniowsk K, Rykowska I, Wasiak W (2011) Is UV and blue-green egg colouration a signal in cavity-nesting birds? Ethol Ecol Evol 23:121-139. https://doi.org/10.1080/03949370.2011. 554882

Wiebe KL, Slagsvold T (2009) Mouth coloration in nestling birds: increasing detection or signalling quality? Anim Behav 78:14131420. https://doi.org/10.1016/j.anbehav.2009.09.013

Zahavi A (1975) Mate selection-a selection for a handicap. J Theor Biol 53:205-214. https://doi.org/10.1016/0022-5193(75)90111-3

Zahavi A (1981) Natural selection, sexual selection and the selection of signals. In: Scudder GGE, Reveal JL (eds) Evolution Today. Carengie-Mellon University Press, Pittsburg, pp 133-138

Publisher's note Springer Nature remains neutral with regard to jurisdictional claims in published maps and institutional affiliations. 